\title{
INTERVIEW
}

For reprint orders, please contact: reprints@futuremedicine.com

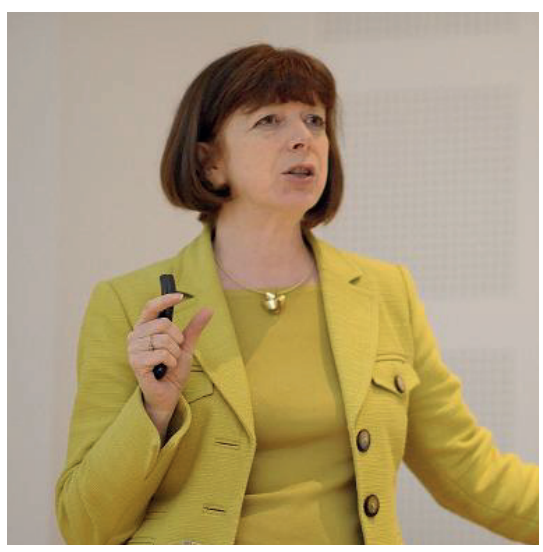

\section{Regenerative medicine research at Pfizer}

\section{Interview with Ruth McKernan}

Ruth McKernan, Chief Scientific Officer at Pfizer Neusentis talks to Regenerative Medicine about the founding of Pfizer's regenerative medicine research program and explains what the recent restructure of the Unit will mean for regenerative medicine at Pfizer.

\section{6 medicine encompassed everything from a small molecule that could modify cell fates, all the way through to cell therapy. $\boldsymbol{9}$}

How did you become involved in the field of regenerative medicine \& stem cell research?

I am a biochemist and pharmacologist by training and part of my formative years were spent setting up phenotypic screening and identifying small molecules through cell-based assays, so I developed an interest in cell biology early on. Once stem cells hit the scientific headlines you could not miss it: it was so exciting! It was something I kept reading about and had my eye on for around 10 years. The idea that embryonic stem cells could be developed into any cell in the body is just so tantalizing.

\section{What led Pfizer to set up Pfizer Regenerative Medicine in 2008 ?}

I had been at Pfizer for a couple of years and had done several different jobs. I was traveling to and from the USA regularly as interim site head of an $R \& D$ center in Boston (MA, USA) and spent a lot of time on the plane asking myself what I wanted to do next. I decided that what I really wanted was to start a research unit in regenerative medicine.
In my mind regenerative medicine encompassed everything from a small molecule that could modify cell fates, all the way through to cell therapy. I encouraged a couple of colleagues, notably Paul Whiting, to help me put together a business proposal to Pfizer to see if we could do that. John McNeish in the USA joined us at a later stage to really hone the proposal. The company liked our proposal, accepted it, and we decided we would split the unit between Cambridge, MA, USA and Cambridge, UK.

Our initial idea was to try to develop at least one program that could move to the clinic in each of the areas that we were interested in: a small molecule that modifies cell fate, an allogeneic cell therapy and an embryonic stem cellderived cell therapy. We considered an autologous cell therapy but we felt that for a large pharmaceutical company the business model to deliver that was not clear, so we decided early on to leave this for a later stage. We could not be in a position where we would need 10 years to get to a product so we deliberately started with key partnerships with companies and academics that we felt were industry-leading. While researching possible collaborations, myself and Paul 
Ruth McKernan is Chief Scientific Officer of Pfizer Neusentis. McKernan is a renowned neuroscientist, author of over 120 publications and a visiting Professor at King's College London. She graduated from the University of London with joint honors in biochemistry and pharmacology and gained her PhD studying the mechanism of action of antidepressant drugs. After 2 years as a researcher at University of California, San Diego she returned to the UK to start a successful career in the pharmaceutical industry. McKernan was instrumental in the creation of Pfizer Regenerative Medicine, hailed by many as the first major foray into the field by big pharma.

Whiting went to a meeting of the British Neuroscience Association and heard Peter Coffey (Institute of Ophthalmology, University College London, UK) talk about his retinal pigment epithelial program for treating macular degeneration. Of all the things we had looked into in the cell therapy area this one really stood out: it required a small number of cells, the eye is an immune privileged site and we had an immediate rapport with the researchers. We formed a collaboration with University College London, which is still going strong. That has been a fantastic example of collaboration between pharma and academia.

In the allogeneic area, we formed a collaboration with a US company, Athersys, Inc. (OH, USA). They are a small company whose multipotent adult progenitor cells are being developed as a product for multiple indications. We agreed with them to conduct a reasonably sized clinical study so that we can understand how and whether bone marrow-derived cells can modify the adult immune system. That clinical study is now up and running in patients with ulcerative colitis. In addition, we started a collaboration with Viacyte (CA, USA) to look at molecules that could help us develop pancreatic $\beta$-cells.

\section{In February, Pfizer Regenerative Medicine's Cambridge, MA, USA site was closed as part of wider changes in the company's}

R\&D strategy. What does this mean for regenerative medicine research at Pfizer?

The restructuring, part of a larger change in the way the Pfizer does its R\&D, meant that we had to close the site in Cambridge, MA, USA and consolidate all of our regenerative medicine onto one site in the UK. That was no reflection on the quality of the work carried out in the USA: our researchers have done some fantastic work and we hope publications around that will be appearing shortly. The restructure allowed us to focus our research in areas of bioinnovation. It was really important that we already had a foothold in Cambridge, UK, and we have now expanded our presence on that site and expanded our research beyond regenerative medicine. We have incorporated Pfizer Regenerative Medicine into a larger unit called Neusentis, derived from 'new science therapeutics'. As well as cell therapy, we are also working on ion channels, sensory disorders and pain. It is a change in the flavor of the unit, but our clinical programs in regenerative medicine continue at full speed.

What are the key regenerative medicine projects that Neusentis will be focusing on going forward?

We are still focusing very much on our retinal epithelial cells program with University College London. The complexity of making these cells and getting through the safety studies makes this a major undertaking and our largest clinical program. We are focusing on quality control for the cells and designing the clinical studies at the moment, but also planning how we would scale-up and scale-out if it delivers what we all hope it will. We also have our adult stem cell therapy program still continuing with Athersys, with biology work ongoing to underpin our understanding of how those cells work and further characterize their potential utility, alongside the clinical study.

How will the development of regenerative medicine therapies differ from small molecule drug development?

It is very different. In some cases, it is actually easier to get to clinical trials, because cell transfer has been used therapeutically for many years (e.g., in bone marrow transplants). However, some aspects of cell therapy are much more difficult. For example, monitoring the cells inside the body is much harder than it is to monitor a small molecule. It is difficult to know what the appropriate dose of the cell is, to track the cells, and to understand how long they stay in the body and where they go. Another major issue is scaling the cells and being able to get them to patients while they are optimally viable: this is a problem that not many have solved. 


\section{I think we can now say that we have the proof of principle that cell therapy can really make a difference to patients. $)$}

$\mathbf{6}$ In terms of our regenerative medicine programs, my main hope is of course to see them working in patients. ?
How would you say the field of regenerative medicine has changed since 2008 when the unit was first founded?

The science has moved incredibly quickly. Based on some of the other landmark achievements, such as the work on trachea replacements, I think we can now say that we have the proof of principle that cell therapy can really make a difference to patients. What we still have to understand is where they will best be placed to help patients. There are so many options and yet so few really robust, large, well controlled clinical studies: there are still enormous gaps in the field.

So how do you see the field and Pfizer's regenerative medicine programs developing?

I wish I had a crystal ball! Things always happen that you do not anticipate, both positive and negative, so I try to avoid speculating about how the field will develop. That said, one has to expect substantial scientific advances in many areas. There will always be a few disappointments when you are making drugs and medicines but I am hoping there will be more successes than disappointments!

In terms of our regenerative medicine programs, my main hope is of course to see them working in patients. Our clinical study in ulcerative colitis is already running and we have safety studies running for our retinal pigment epithelial program. Obviously, we need to demonstrate the safety in preclinical studies first, but provided we do not uncover any safety issues we could be in clinical trials with patients next year.

Financial \& competing interests disclosure

The author has no relevant affiliations or financial involvement with any organization or entity with a financial interest in or financial conflict with the subject matter or materials discussed in the manuscript. This includes employment, consultancies, honoraria, stock ownership or options, expert testimony, grants or patents received or pending, or royalties.

No writing assistance was utilized in the production of this manuscript. 